\title{
Microstructural designs of spark-plasma sintered silicon carbide ceramic scaffolds
}

\author{
B. ROMÁN-MANSO, Á. DE PABLOS, M. BELMONTE, M. I. OSENDI, P. MIRANZO \\ Instituto de Cerámica y Vidrio (ICV-CSIC), Madrid 28049, España
}

\begin{abstract}
Concentrated ceramic inks based on $\beta$-SiC powders, with different amounts of $\mathrm{Y}_{2} \mathrm{O}_{3}$ and $\mathrm{Al}_{2} \mathrm{O}_{3}$ as sintering aids, are developed for the adequate production of $\mathrm{SiC}$ scaffolds, with different patterned morphologies, by the Robocasting technique. The densification of the as-produced 3D structures, previously heat treated in air at $600^{\circ} \mathrm{C}$ for the organics burn-out, is achieved with a Spark Plasma Sintering (SPS) furnace. The effects of the amount of sintering additives $(7-20$ wt. \%) and the size of the $\mathrm{SiC}$ powders $(50 \mathrm{~nm}$ and $0.5 \mu \mathrm{m})$ on the processing of the inks, microstructure, hardness and elastic modulus of the sintered scaffolds, are studied. The use of nano-sized $\beta$-SiC powders significantly restricts the attainable maximum solids volume fraction of the ink (0.32 compared to 0.44 of the submicron-sized powders-based ink), involving a much larger porosity of the green ceramic bodies. Furthermore, reduced amounts of additives improve the mechanical properties of the ceramic skeleton; particularly, the stiffness. The grain size and specific surface area of the starting powders, the ink solids content, green porosity, amount of sintering additives and SPS temperatures are the main parameters to be taken into account for the production of these SiC cellular ceramics.
\end{abstract}

Keywords: Silicon carbide, Robocasting, spark plasma sintering, ceramic scaffolds, mechanical properties

Diseño microestructural de andamiajes cerámicos de SiC sinterizados por corriente eléctrica pulsada

Se han fabricado andamiajes de carburo de silicio $(\mathrm{SiC})$ usando la técnica de "Robocasting", a partir de tintas cerámicas conteniendo $\beta-\mathrm{SiC}$ y distintas cantidades de $\mathrm{Y}_{2} \mathrm{O}_{3}$ and $\mathrm{Al}_{2} \mathrm{O}_{3}$, como aditivos de sinterización. La densificación de las estructuras tridimensionales, previamente calcinadas a $600^{\circ} \mathrm{C}$ para eliminar los aditivos orgánicos, se realizó en un horno de "Spark Plasma Sintering" (SPS). Se analizó el efecto de la cantidad de aditivos de sinterización (7-20\% en peso) y del tamaño de partícula inicial del polvo de $\mathrm{SiC}(50 \mathrm{~nm}$ y $0.5 \mu \mathrm{m})$ en el procesado de las tintas, en la microestructura, la dureza y el módulo elástico de las estructuras sinterizadas. El uso de polvo nanométrico restringió significativamente la fracción máxima de sólidos alcanzable (0.32 frente a 0.44 de la tinta de $\mathrm{SiC}$ submicrométrico), lo que condujo a una mayor porosidad de los andamiajes en verde. Una reducción del contenido de aditivos produjo aumentos en la dureza y módulo elástico del esqueleto cerámico. El tamaño de partícula y la superficie específica del polvo de partida, el contenido en sólidos, la porosidad en verde, y cantidad de aditivos y temperatura de sinterización, fueron los parámetros esenciales para la producción de estas cerámicas celulares de SiC.

Palabras clave: carburo de silicio, Robocasting, sinterización por corriente eléctrica pulsada (SPS), andamiajes cerámicos, propiedades mecánicas

\section{INTRODUCTION}

Cellular materials are an important kind of high-porosity solids comprising structures like certain foams, honeycombs or robocast scaffolds, which exhibit remarkable properties, such as low density, low thermal conductivity, large exposed surface and, especially, relatively high mechanical resistance [1-4]. The major appeal of cellular ceramics is based on their wide range of applications $[5,6]$ like chemically inert filters, thermal storage systems, heat exchangers, catalytic supports, or as scaffolds for osteo-integration.

As an exceptional example of structural ceramics, the family of $\mathrm{SiC}$ materials stands out for a combination of excellent properties, particularly their low density, high hardness, high stiffness, and high resistance to abrasion, corrosion and wear, even at high temperatures $[7,8]$. These properties enable the use of $\mathrm{SiC}$ either in bulk or as a cellular material for certain severe applications.
Three main processing routes have been reported for the manufacture of porous structures, namely, foaming routes, the use of sacrificial templates, and solid freeform fabrication processes [9,10]. Structural macroporous $\mathrm{SiC}$ components have been produced by replicating polymer foams [11] or wood templates [12,13], or by using other sacrificial organic templates (e.g. PMMA [14] or nylon [15]), and inorganic materials (such as graphite and $\mathrm{SiO}_{2}$ [14]). Other methods as direct foaming [16] have also been attempted for $\mathrm{SiC}$.

The Robocasting technique was originally developed as a rapid prototyping system for forming $3 \mathrm{D}$-complex components by taking advantage of the knowledge on the colloidal processing of ceramics [10,17]. Robocasting consists in a concentrated colloidal ink (analogous to a slurry for a 3D printing process) extruded through a nozzle or tip forming a continuous filament, 
TAble 1. POWder mixture COMPOSITIONS, PRINTABle INK FORMUlATIONS AND SINTERING PARAMETERS OF THE STUdied SiC-BASED ROBOCAST SCAFFOLDS.

\begin{tabular}{|c|c|c|c|c|}
\hline \multicolumn{2}{|c|}{ Material } & $\beta 20$ (micro) & N20 (nano) & $\beta 7$ (micro) \\
\hline \multirow{4}{*}{$\begin{array}{c}\text { Powder } \\
\text { Composition }\end{array}$} & $\beta-\operatorname{SiC}(w t . \%)$ & 80.0 & 80.0 & 93.0 \\
\hline & $\mathrm{Al}_{2} \mathrm{O}_{3}(\mathrm{wt} . \%)$ & 8.6 & 8.6 & 2.0 \\
\hline & $\mathrm{Y}_{2} \mathrm{O}_{3}($ wt. $\%)$ & 11.4 & 11.4 & 5.0 \\
\hline & S.S. $\left(m^{2} \cdot g^{-1}\right)$ & $14.8 \pm 0.1$ & $26.2 \pm 0.2$ & $16.1 \pm 0.1$ \\
\hline \multirow{7}{*}{ Ink composition } & Solids Loading (wt.\%) & 72.5 & 61.2 & 71.4 \\
\hline & Solids Loading (vol.\%) & 43.8 & 31.8 & 42.5 \\
\hline & H-PEI (wt.\%) & 2 & 3.7 & 2.6 \\
\hline & L-PEI (wt.\%) & 2.1 & 3.6 & 2.8 \\
\hline & APA (wt. $\%)$ & 0.5 & 0.4 & 0.3 \\
\hline & F4M (wt. $\%)$ & 3.6 & 6.1 & 4.8 \\
\hline & Total additives (wt.\%) & 8.2 & 13.8 & 10.5 \\
\hline \multicolumn{2}{|c|}{ Sintering temperature $\left({ }^{\circ} \mathrm{C}\right)$} & 1700 & 1750 & 1800 \\
\hline \multicolumn{2}{|c|}{ Linear Shrinkage (\%) } & 23 & 28 & 19 \\
\hline \multicolumn{2}{|c|}{$\rho_{\text {app }}\left(\mathrm{g} \cdot \mathrm{cm}^{-3}\right)$} & 3.34 & 3.31 & 3.23 \\
\hline \multicolumn{2}{|c|}{ Weight loss (\%) } & $8.4 \pm 0.5$ & $11.6 \pm 0.9$ & $11.1 \pm 0.4$ \\
\hline
\end{tabular}

Label used for each SiC-based ceramic material; composition and specific surface area (S.S.) of the powder mixtures; solids loadings and organic additive compositions of the printable SiC inks; sintering temperature, shrinkage and weight loss during SPS, and apparent density $\left(\rho_{\text {app }}\right)$ of the sintered structures.

which is placed onto a substrate to assemble the final 3D pattern in a succession of building layers. The retention of shape by the formed filaments is basically accomplished by a precise control over the ink viscosity, employing high solids loadings for minimizing the shrinkage during the drying process and, thus, preventing cracking phenomena. In this way, robocasting has been proved suitable for many ceramics such as silica [17], alumina [18], tricalcium phosphate [19] or hydroxyapatite [20], all of which can be easily densified in conventional furnaces in air atmospheres. Furthermore, the challenge of fabricating non-oxide ceramic scaffolds by robocasting has already been demonstrated [21], employing $\mathrm{SiC}$ inks containing submicronic $\mathrm{SiC}$ powders and $20 \mathrm{wt}$. $\%$ of sintering aids $\left(\mathrm{Al}_{2} \mathrm{O}_{3}\right.$ and $\left.\mathrm{Y}_{2} \mathrm{O}_{3}\right)$ to obtain complex 3D structures densified by Spark Plasma Sintering (SPS).

In the present work, a deeper analysis of the microstructural features and their influence on the hardness and stiffness of $\mathrm{SiC}$ scaffolds is presented. At the same time, reduced amounts of sintering additives were explored for a better mechanical performance and a novel colloidal ink was formulated using nano-sized SiC powders. The importance of developing inks of nanosized powders, extruded through extremely narrow tips avoiding most clogging phenomena, has already been shown by Sun et al. [22] for a highly precise patterning of structures (in particular, interdigitated arrangements).

\section{EXPERIMENTAL PART}

The selected ceramic powders were submicron- $\beta$-SiC $\left(\mathrm{d}_{50}=0.5 \mu \mathrm{m}, \mathrm{B}-17\right.$ H.C. Starck GmbH, Goslar, Germany) and nano- $\beta$-SiC (NanoAmor, $d_{50}=45-55 \mathrm{~nm}$, polytype $3 \mathrm{C}$ ), using $\mathrm{Al}_{2} \mathrm{O}_{3}\left(\mathrm{~d}_{50}=0.37 \mu \mathrm{m}, \mathrm{CR}-15\right.$; Baikalox, Annecy, France) and $\mathrm{Y}_{2} \mathrm{O}_{3}$ $\left(\mathrm{d}_{50}=2.09 \mu \mathrm{m}, \mathrm{AT}\right.$; H.C.Starck, $\left.\mathrm{GmbH}\right)$ as sintering additives. Three different inks were prepared from distinct SiC-based powder compositions, as shown in Table 1.
Inks were prepared following the same procedure as described elsewhere [21]. In short, $\mathrm{SiC}: \mathrm{Al}_{2} \mathrm{O}_{3}: \mathrm{Y}_{2} \mathrm{O}_{3}$ powder mixtures were initially homogenized by attrition milling using isopropyl alcohol as the solvent and alumina balls as the grinding media. After solvent removal in a rotary evaporator and drying in an oven at $120^{\circ} \mathrm{C}$, the specific surface area of every powder mixture was measured by one-point BET $\mathrm{N}_{2}$ adsorption (Monosorb QuantaChrome, Model MS-13, FL, USA). A sequential process was used to achieve printable inks: a well-dispersed suspension of high solids loadings was first created by adding the powders to an aqueous polymer solution of a moderately charged cationic polyelectrolyte dispersant, and then, a viscosifier was added resulting in a weak gel. Next, controlled flocculation was provoked by adding a counter poly-electrolyte creating a strong colloidal gel with high solids loadings, showing pseudoplastic behavior. Both, high molecular weight polyethylenimine (H-PEI, Mw $=25000$ g. $\mathrm{mol}^{-1}, 50$ wt. \%; Aldrich Chemical Co. Milwaukee, WI) and low molecular weight PEI (L-PEI, Mw $=2000 \mathrm{~g} \cdot \mathrm{mol}^{-1}, 50$ wt. \%; Aldrich Chemical Co. Milwaukee, WI) were used as dispersants. Ceramic compositions were gradually added and homogenized in a planetary centrifugal mixer (ARE250; Thinky Company, Laguna Hills, CA). Methylcellulose (Methocel F4M, Mw=3500 g. $\mathrm{mol}^{-1}, 10$ wt. \%; Dow Chemical Company, Midland, MI) was added as viscosifier to prevent phase separation during ink extrusion. Finally, ammonium polyacrylate (APA) (Darvan-821; R. T. Vanderbilt Company, Inc., Norwalk, CT) was used as flocculant.

The viscosity of the slurries was determined with a rheometer (CVO 100 D, Bohlin Instruments, UK) equipped with cone-and-plate geometry (diameter: $40 \mathrm{~mm}$; cone angle: $4^{\circ}$ ). The rheometer measuring system was covered with a fitting tool to reduce evaporation. The apparent viscosity $\left(\eta_{\text {app }}\right)$ of the inks was measured as a function of increasing shear rate (from $\dot{\gamma}=0.01-150 \mathrm{~s}^{-1}$ at 20 discrete points with logarithmic 


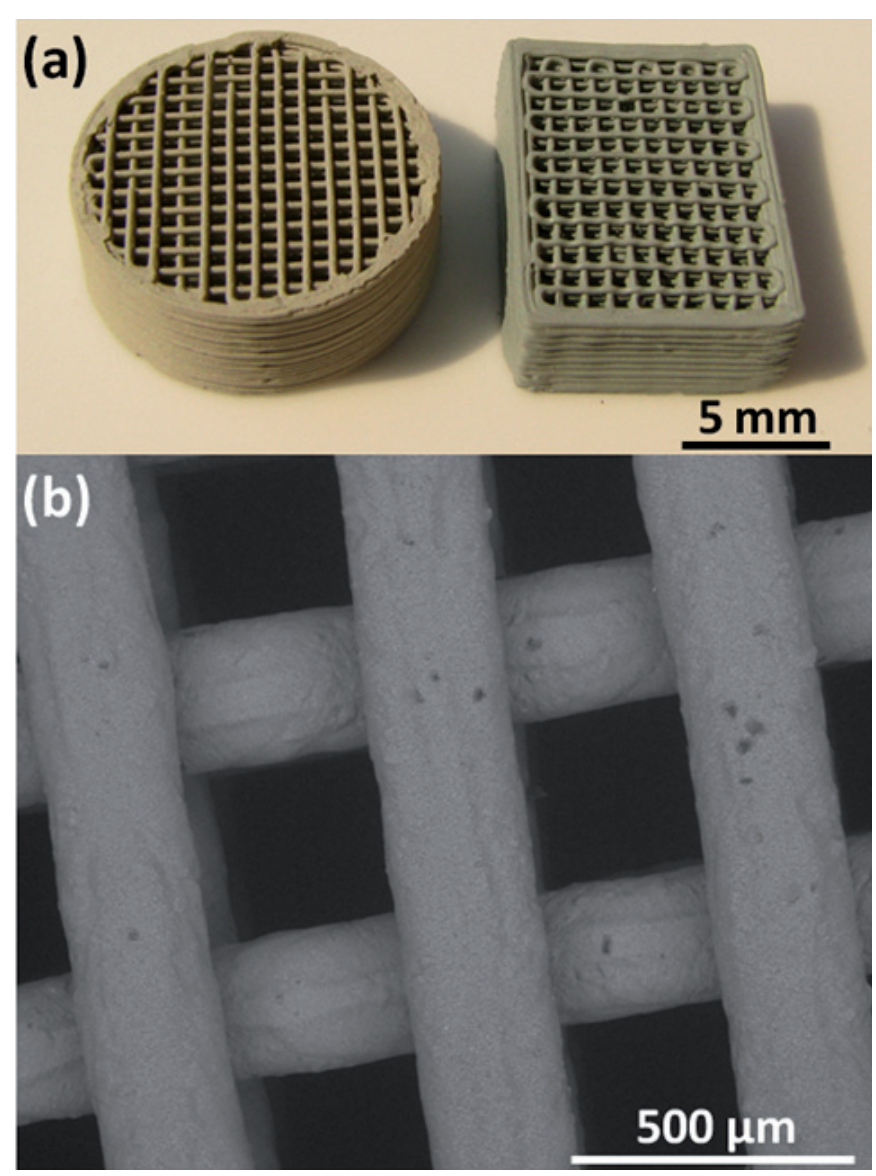

Figure 1. (a) Round and rectangular $\mathrm{SiC}$ scaffolds in their green state fabricated by the Robocasting technique with the $\beta 7$ and N20 compositions, respectively, and (b) SEM image of the rods of two adjacent layers of a $\beta 7$ lattice.

spacing); a pre-shearing of $1 \mathrm{~s}^{-1}$ for a period of $60 \mathrm{~s}$ and a following equilibration (zero shear rate rest) time of $100 \mathrm{~s}$ were carried out before each test.

Cylindrical and rectangular lattices were prototyped with designing software (RoboCAD 4.0, 3-D Inks LLC, Stillwater, $\mathrm{OK})$ and printed with a custom three-axis robocasting system (A-3200, 3-D Inks LLC) at room temperature. Syringes of $3 \mathrm{~cm}^{3}$ (EFD Inc., East Providence, RI, USA) were used. The ink was then extruded through nozzles (Precision Tips; EFD Inc.) with diameters ranging 250-330 $\mu \mathrm{m}$ onto flat alumina substrates immersed in a paraffin oil bath to avoid drying during printing. The extrusion speed of the ink was controlled by an automatic feed system at a constant volumetric flow rate of $0.25 \pi \mathrm{D}^{2} v$, where $\mathrm{D}$ is the inner diameter of nozzle and $v$ is the constant $x-y$ table speed $\left(10 \mathrm{~mm} \cdot \mathrm{s}^{-1}\right.$ for the present structures). Lattices were assembled by depositing a linear array of parallel filaments in the $x-y$ plane such that they are orthogonal in adjacent layers. The designed cylindrical and rectangular lattices with $\mathrm{N}$ layers (typically 20) are shown in Figure 1. Once the required height was reached, the scaffold was removed from the oil bath and dried at room temperature.

As-dried samples were put in a conventional box furnace at $600{ }^{\circ} \mathrm{C}$ for $2 \mathrm{~h}$ in air to burn out the organic additives, and afterwards, sintered in the spark plasma furnace (SPS, Dr. Sinter, SPS-510CE; SPS Syntex Inc., Kanagawa, Japan). The SPS tests were carried out at maximum temperatures of 1700 $-1800{ }^{\circ} \mathrm{C}$, using a heating rate of $133^{\circ} \mathrm{C} \cdot \mathrm{min}^{-1}$ between $600{ }^{\circ} \mathrm{C}$ and $1400{ }^{\circ} \mathrm{C}$, reduced to $50{ }^{\circ} \mathrm{C} \cdot \mathrm{min}^{-1}$ from $1400{ }^{\circ} \mathrm{C}$ to the set point temperature, and ending with 5 min of holding time at the maximum temperature. All sintering runs were carried out in argon atmosphere, using a special die tool [21], purposely designed to avoid the collapse of the 3D structures, when load was applied.

Apparent density of the as-sintered ceramic skeletons was measured by the water immersion method. Theoretical densities of $3.44 \mathrm{~g} \cdot \mathrm{cm}^{-3}$ for the $\beta 20$ and N20 compositions, and $3.28 \mathrm{~g} \cdot \mathrm{cm}^{-3}$ for the $\beta 7$ were estimated, according to compositions and densities of the original powders $\left(\rho(\mathrm{SiC})=3.21 \mathrm{~g} \cdot \mathrm{cm}^{-}\right.$ 3, $\left.\rho\left(\mathrm{Y}_{2} \mathrm{O}_{3}\right)=5.01 \mathrm{~g} \cdot \mathrm{cm}^{-3}, \rho\left(\mathrm{Al}_{2} \mathrm{O}_{3}\right)=3.97 \mathrm{~g} \cdot \mathrm{cm}^{-3}\right)$. Weight and geometric changes of the ceramic lattices during sintering were also measured.

The crystalline phases were analyzed by X-ray diffraction procedures (XRD; Siemens D5000, Munich, Germany), using $\mathrm{CuK} \alpha$ radiation $\left(\mathrm{K}_{\alpha 1}=1.5406 \AA\right.$, in an angle of detection $10^{\circ}<2 \theta<80^{\circ}$ with a scanning rate of $\left.2^{\circ} \cdot \mathrm{min}^{-1}\right)$. A confocal microRaman spectrometer (Alpha300, WITec GmbH, Germany) was employed to obtain Raman spectra and maps at room temperature on polished cross sections of the structures with an acquisition range from 200 to $3000 \mathrm{~cm}^{-1}$, and using a laser wavelength excitation of $532 \mathrm{~nm}$, for additional phase characterization. Raman maps of $60 \times 60$ pixels, recording one spectrum per pixel and using $100 \mathrm{~ms}$ of acquisition time, were acquired in $10 \mu \mathrm{m} \times 10 \mu \mathrm{m}$ scanned areas.

The specimens were observed at low magnification in a tabletop scanning electron microscope (SEM, TM-1000; Hitachi, Tokyo, Japan). The microstructure of the samples was analyzed on polished and $\mathrm{CF}_{4}-5 \% \mathrm{O}_{2}$ plasma etched surfaces of cross sectioned lattice rods by using a field emission scanning electron microscope (FESEM; Hitachi S-4700, Tokyo, Japan). The size and aspect ratio distributions of the $\mathrm{SiC}$ grains as well as the porosity area fraction were estimated by image analysis using the J-image software on FESEM micrographs by considering at least 400 features.

Elastic modulus $(\mathrm{E})$ and hardness $\left(\mathrm{H}_{\mathrm{v}}\right)$ at room temperature were evaluated by depth sensing indentation methods (Zwick/ Roell, Zhu 2.5, Germany) using a Vickers pyramidal indenter at a force of $10 \mathrm{~N}$ on the cross-sections of the skeleton rods embedded in a resin; at least seven well-defined indentations were considered for each material, and the mean and deviation of the measured values were reported. The E value was obtained from the unloading curve using the OliverPharr method [23] and correction from the frame compliance. Additional micro-indentation tests were also performed at a $0.5 \mathrm{~N}$ load (Microindenter (UMT-2, Bruker, formerly CETR, Germany) on the fabricated scaffolds and on a reference bulk $\mathrm{SiC}$ specimen, in order to check the feasibility of the technique at $10 \mathrm{~N}$ load.

\section{RESULTS AND DISCUSSION}

The colloidal inks for robocasting should accomplish two key conditions $[10,17,18]$ : shear thinning rheological behavior to enable extrusion through fine deposition nozzles with rapid recovery of yield stress after deposition, and high solids loadings to limit shrinkage and stress upon drying. As the surface of $\mathrm{SiC}, \mathrm{Al}_{2} \mathrm{O}_{3}$ and $\mathrm{Y}_{2} \mathrm{O}_{3}$ particles must be covered with dispersant molecules, which govern the surface characteristics, in order to get similar zeta potential behavior for the three components, the 


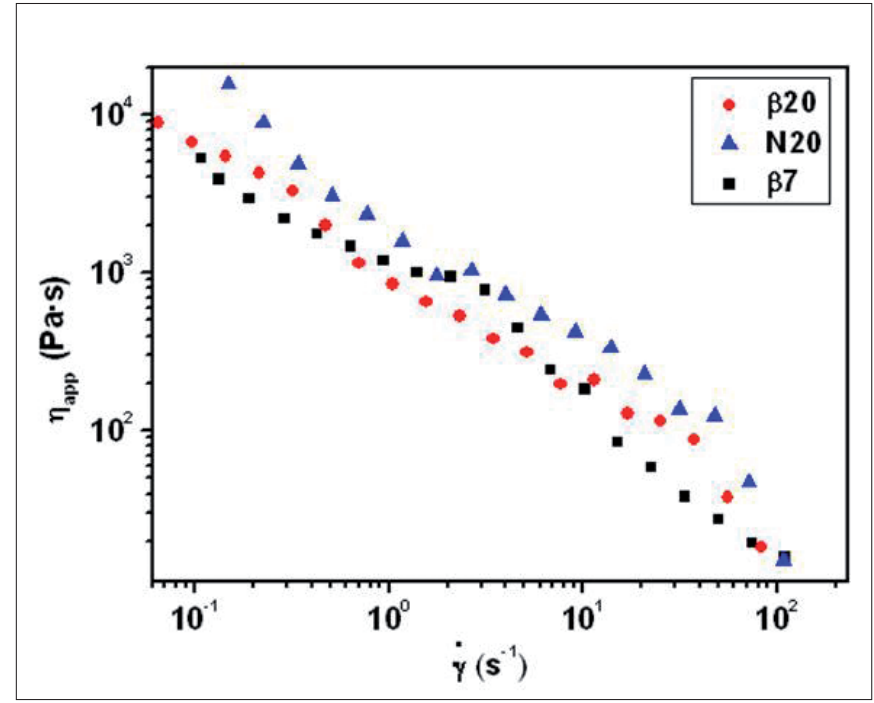

Figure 2. Log-log plot of apparent viscosity $\left(\eta_{\text {app }}\right)$ versus shear rate ( $\dot{\gamma}$ ) for the three SiC inks formulated according to Table 1.
Regarding the maximum solids fraction achievable in the pastes, while keeping the desired rheological behavior, an evident relation with the grain size of the starting powders is drawn: whereas it is similar $(\sim 0.44)$ for the $\beta 7$ and $\beta 20$ compositions, it is drastically reduced $(\sim 0.32)$ in the case of the N20. The green densities of the N20 scaffolds are therefore expected to be reduced by $\sim 25-30 \%$, so that the subsequent sintering process will be hindered.

As shown in Figure 2, the rheology of the formulated SiC inks (Table 1) is highly shear thinning, and similar slopes of the apparent viscosity $\left(\eta_{\text {app }}\right)$ versus shear rate $(\dot{\gamma})$ curves are observed for the three cases. These results are also quite similar to those reported in a previous work for the $\beta 20$ composition [21] using, in that case, a serrated cup and bob measuring system. The as-generated gels were pressure extruded through the nozzles in the working shear rate region of 30 to $70 \mathrm{~s}^{-1}$. Typical structures assembled by robocasting are shown in Figure 1. Neither bending nor cracking were detected and, therefore, the pastes were of sufficient strength to retain the shape of the extruded filaments and the overall geometry of the deposited lattice structures, even for the N20 powders composition of significant lower solids contents.

\section{Calcined rod at $600^{\circ} \mathrm{C}$}

\section{Sintered rod at $1700^{\circ} \mathrm{C}$}
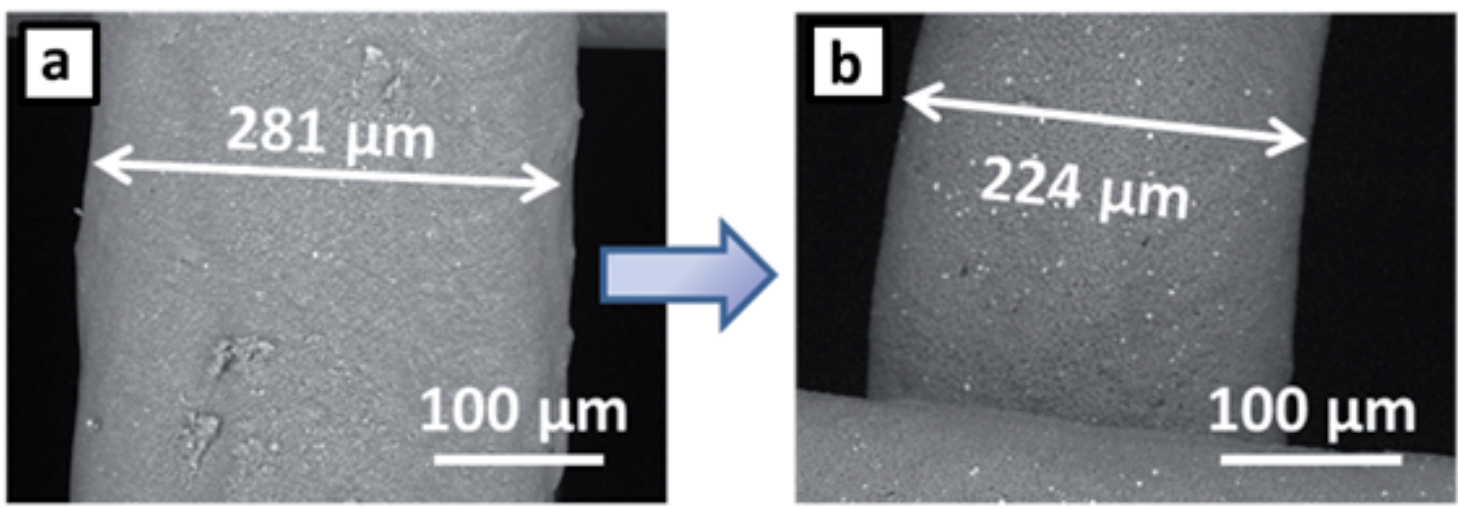

Figure 3. SEM micrographs of two $\mathrm{SiC}$ rods ( $\beta 20$ composition) belonging to the same sample after organics burn-out at $600{ }^{\circ} \mathrm{C}(\mathrm{a})$ and $\mathrm{SPS}$ at $1700{ }^{\circ} \mathrm{C}(\mathrm{b})$, showing the $\sim 20 \%$ shrinkage during the densification.

required amount of PEI is directly related to the total surface area of the ceramic powders in the suspension (calculated from the solids content and the specific surface area collected in Table 1), resulting in the proportions of $2 \mathrm{mg} \cdot \mathrm{m}^{-2}$ of $\mathrm{H}$-PEI plus 2 $\mathrm{mg} \cdot \mathrm{m}^{-2}$ of L-PEI. The longer branches of H-PEI help to maintain larger electrosteric forces between particles, allowing higher solids volume contents, whereas the use of L-PEI is required for achieving satisfactory shear-thinning behavior; the use of only $\mathrm{H}-\mathrm{PEI}$ precludes the development of 3D-structures due to a lack in the required pseudoplasticity of the ink, therefore attainable by the combined action of H-PEI and L-PEI. On the contrary, the amount of the APA needed to collapse the electrosteric forces of the adsorbed dispersant molecules, for achieving a controlled flocculation of the ink, did not depend strongly on the surface area, being in the $0.3-0.5$ wt. \% range. A viscosifying agent (Methocel F4M) was added to avoid phase segregations in the gel during extrusion, thus maintaining the colloidal structure; and it was also chosen proportional to the surface area of the ceramic composition in the suspension, and equivalent to the added amount of L-PEI plus H-PEI ( 0.9 times). The composition of the three inks is presented in Table 1.
The SPS temperatures shown in Table 1 were selected based on previous results for the corresponding bulk materials [24] to assure an adequate densification under the present conditions. In this way, a temperature of $1700{ }^{\circ} \mathrm{C}$ was selected for the composition $\beta 20$, and increased up to $1800{ }^{\circ} \mathrm{C}$ for $\beta 7$, according to the reduction from 20 to $7 \mathrm{wt} \%$ in the sintering aids. In the case of the N20 structures, a temperature of $1750{ }^{\circ} \mathrm{C}\left(50{ }^{\circ} \mathrm{C}\right.$ above that used for $\left.\beta 20\right)$ was chosen due to its lower degree of compaction associated to the lower solids loading of this ink. During the SPS process, the SiC scaffolds and the lattice rods experienced significant isotropic shrinkage (Figure 3). Comparing lattices for the two compositions with similar amount of additives (20 wt. \%), shrinkage was larger for the N20 (28\%) than for the $\beta 20(23 \%)$ scaffolds, due to a lower density in the green state of the former (from a lower solids content of the corresponding ink, see Table 1). The smaller shrinkage observed for the $\beta 7$ scaffolds (19\%) may probably be attributed to an insufficient amount of liquid phase formed during the sintering process, which would limit the full densification of the SiC skeleton under pressureless conditions. The porosity fraction measured on 


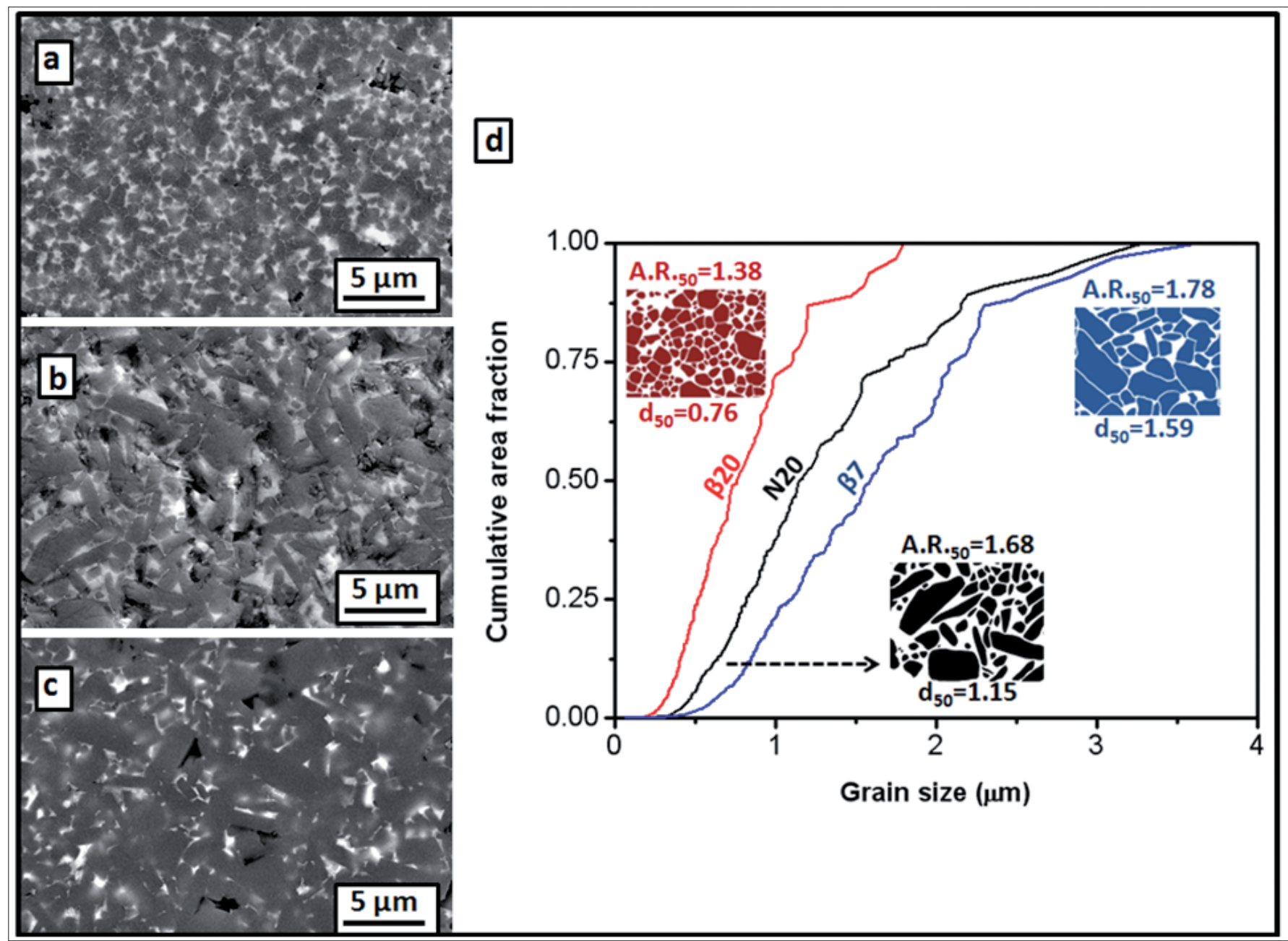

Figure 4. FESEM micrographs of the polished and $\mathrm{CF}_{4} / \mathrm{O}_{2}$ plasma etched cross-sections of the sintered scaffold rods for (a) $\beta 20$, (b) N20 and (c) $\beta 7$. (d) Corresponding $\mathrm{SiC}$ cumulative grain size distributions measured by image analysis on FESEM images. The median grain size $\left(\mathrm{d}_{50}\right)$ and aspect ratio $\left(\mathrm{AR}_{50}\right)$ data are also included in the figure.

the $\mathrm{SiC}$ rods by image analysis was estimated as $0.9,1.6$ and $9.5 \%$ for $\beta 20, \beta 7$ and N20, respectively. The case of the N20 scaffolds is especially remarkable; despite the temperature raise (from 1700 to $1750{ }^{\circ} \mathrm{C}$ ) and the superior shrinkage, the porosity level was by far the largest, which emphasizes the significance of achieving a high solids loading in the printing ink. The total weight loss (Table 1) after sintering was 8,11 and 12 wt. $\%$ for the $\beta 20, \beta 7$ and N20 scaffolds, respectively, attributable to decomposition/volatilization processes of the more unstable ceramic phases, as organic additives present in the calcined structures were mainly eliminated by the heat treatment in air at $600^{\circ} \mathrm{C}$, which produced a weight loss of $\sim 5$ wt. \% [21].

As seen in Figure 4, the sintering additives (bright phase in the images) are well distributed within the $\mathrm{SiC}$ matrix for the three compositions. In this figure, important differences in the grain size are observed, which seem to be mainly related to the SPS temperature, as expected. Quantitative image analysis data confirm that the N20 samples have a median grain size $(1.15 \mu \mathrm{m}) 1.5$ times higher than that of $\beta 20(0.76 \mu \mathrm{m})$. This fact can be related to their higher sintering temperature $\left(1750{ }^{\circ} \mathrm{C}\right.$ versus $\left.1700{ }^{\circ} \mathrm{C}\right)$. However, the effect of the more reactive character of the nano-SiC powder as well as its higher oxygen content [24] would also lead to a faster sintering rate and grain growth kinetics. Furthermore, N20 specimens clearly developed elongated $\mathrm{SiC}$ grains of median aspect ratio $\mathrm{AR}_{50}=$ 1.68 as compared to 1.38 for $\beta 20$ (Fig. 4). The highest grain size was observed in the rods of the $\beta 7$ lattice $\left(\mathrm{d}_{50}=1.59 \mu \mathrm{m}\right.$ and $\left.\mathrm{AR}_{50}=1.78\right)$, densified at the highest SPS temperature.

A comparison with a bulk $\mathrm{SiC}$ material of the same composition as $\beta 7$, also densified by SPS at $1800^{\circ} \mathrm{C}$ in Ar under a uniaxial pressure of $50 \mathrm{MPa}$, shows significantly higher values ( 3 and 1.5 times higher for $\mathrm{d}_{50}$ and $\mathrm{AR}_{50}$, respectively) for the robocast specimens than those observed in bulk $\mathrm{SiC}$ $\left(\mathrm{d}_{50}=0.54 \mu \mathrm{m}\right.$ and $\left.\mathrm{AR}_{50}=1.30\right)$, which is an indication that the robocast specimens withstood temperatures above those measured by the controlling pyrometer. As seen in Figure 5, higher electrical power was dissipated during the SPS tests in the case of robocast $\mathrm{SiC}$ (8.2 MJ by integrating on time) than in the runs of bulk $\mathrm{SiC}$ specimens of the $\beta 7$ composition $(7.7 \mathrm{MJ})$, both at $1800{ }^{\circ} \mathrm{C}$. A higher self-heating of the lattice structure produced by Joule effect is inferred, explained by the fact that a higher current density flows through the $\mathrm{SiC}$ rods, as well as the effects of radiation phenomena within the graphite chamber due to the macroporous nature of the scaffolds. 


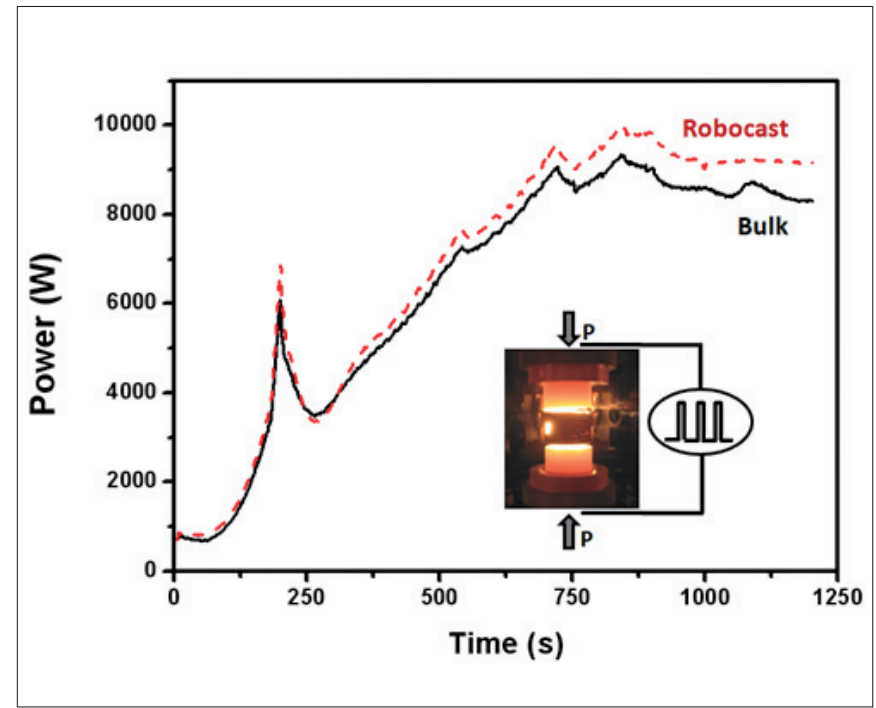

Figure 5. Power versus time during SPS of a $\beta 7$ bulk SiC and a $\beta 7$ robocast specimen sintered in $\mathrm{Ar}$ at $1800{ }^{\circ} \mathrm{C}$.
$\mathrm{SiC}$, the $\mathrm{G}$ band at $1575 \mathrm{~cm}^{-1}$ of any carbonaceous species, and also a $630 \mathrm{~cm}^{-1}$ band, ascribed to either the $\mathrm{AlY}_{3} \mathrm{C}_{0.5}$ reaction product or the $\mathrm{YAlO}_{3}$ grain boundary phase according to the XRD pattern. The spectra at the position where maximum intensity of each of these bands is recorded are also shown in the Figure 6c. The high temperatures developed during SPS of robocast specimens then favor grain growth and SiC decomposition, and the reaction of carbon with the sintering additives.

Indentations at two different loads $(0.5$ and $10 \mathrm{~N})$ were performed on the polished cross sections of the $\mathrm{SiC}$ rods forming the scaffolds for a mechanical characterization (see example in Figure 7a). The loading-unloading curves of the force vs. indentation depth at $10 \mathrm{~N}$ for $\beta 7$ and $\beta 20$ are shown in Figure $7 \mathrm{~b}$, demonstrating the more compliant behavior of the latter due to its higher content of sintering additives and smaller grain size. As shown in the Table of Figure 7c, the elastic moduli of the $\beta 20$ and N20 rods were lower than that for $\beta 7$ rods (exhibiting 13-17\% increase), at both of the tested loads, thus enabling to produce SiC scaffolds with tailored stiffness by varying the amount of sintering aids. It should be
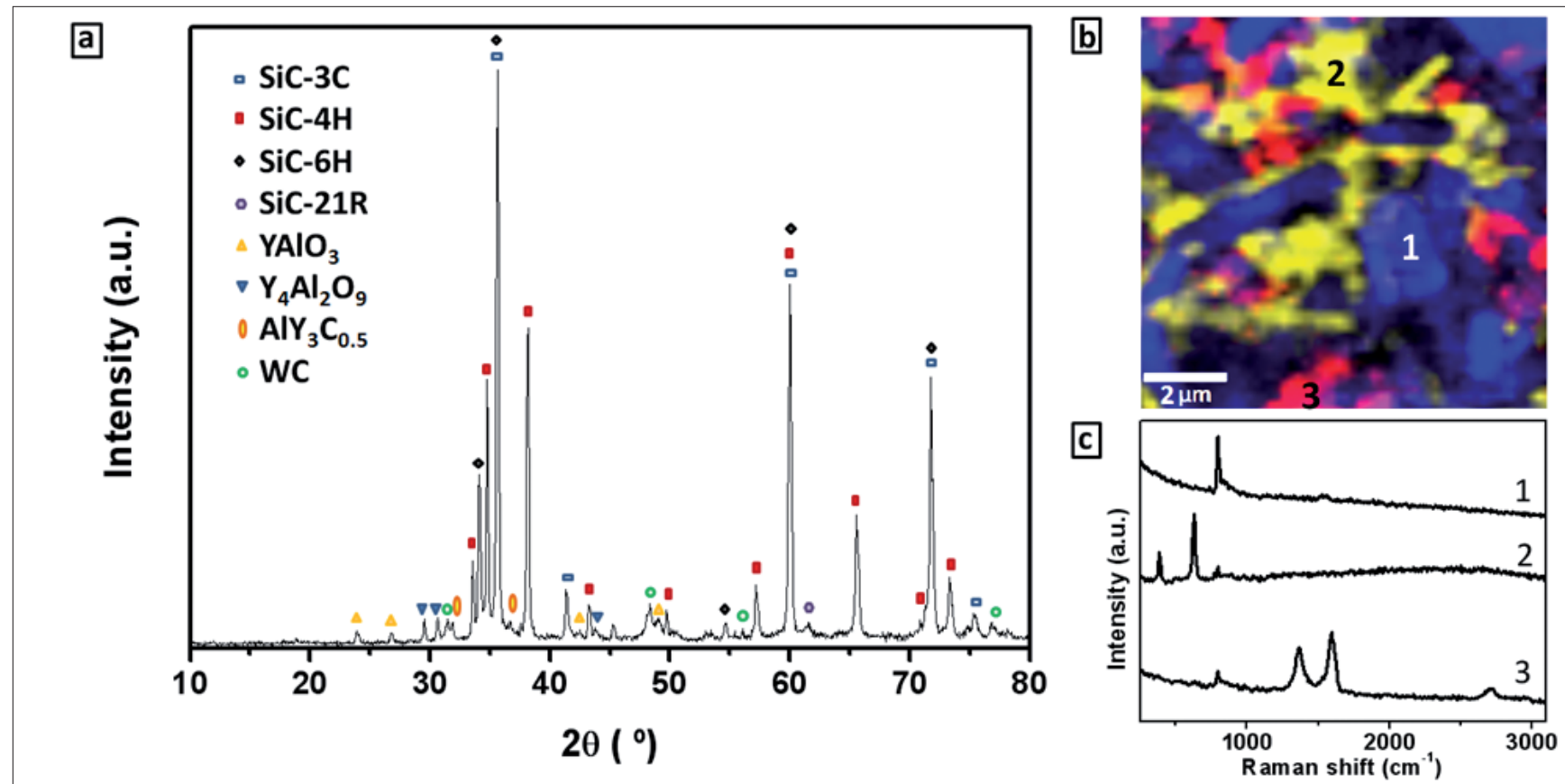

Figure 6. Analysis of the crystalline phases in the $\beta 7$ robocast specimen: (a) XRD pattern of a powdered specimen (WC contamination comes from the mechanical miller); (b) Raman image (in false colours) constructed by mapping the intensity of the $796 \mathrm{~cm}^{-1} \mathrm{band}$ of $\mathrm{SiC}(1)$, the $630 \mathrm{~cm}^{-1} \mathrm{band}$ of the grain boundary phases, either $\mathrm{AlY}_{3} \mathrm{C}_{05}$ or $\mathrm{YAlO}_{3}(2)$ and the $\mathrm{G}$ band at $1575 \mathrm{~cm}^{-1}$ of carbonaceous species (3); and (c) single spectra of each of these phases marked with numbers on the map.

These high temperatures directly affect the crystalline phases formed in the $\mathrm{SiC}$ ceramic skeletons. Specimens sintered at nominal temperatures above $1750^{\circ} \mathrm{C}$, i.e. $\mathrm{N} 20$ and $\beta 7$, showed a high degree of $\beta-\rightarrow \alpha-S i C$ phase transformation, with peaks associated to different hexagonal and rombohedral polytypes, more stable at these high temperatures, as observed in Figure 6 a for a $\beta 7$ specimen. Furthermore, additional peaks ascribed to a cubic aluminum yttrium carbide phase were detected. The presence of such high-temperature-related phases was also confirmed by Raman spectroscopy. Three different phases are observed in Raman images (Figure 6b) constructed by mapping the intensity of the $796 \mathrm{~cm}^{-1}$ band of noted that the elastic modulus values at $10 \mathrm{~N}$ were significantly lower than those measured at $0.5 \mathrm{~N}$ for all the scaffolds. Conversely, the $\mathrm{E}$ value observed in the case of the $\beta 7$ bulk specimen at $0.5 \mathrm{~N}(406 \pm 13 \mathrm{GPa})$ is similar to that reported for higher indentation loads (430 $\pm 25 \mathrm{GPa}$ [25]) A possible explanation for this may be related to the compliance of the resin in which the specimens are embedded for the indentation tests, which is especially remarkable for the robocast rods of $\sim$ $220 \mu \mathrm{m}$ diameter than for the larger bulk specimens ( $3 \mathrm{~mm} \times 20$ $\mathrm{mm})$. Therefore, more realistic $\mathrm{E}$ values are those measured using $0.5 \mathrm{~N}$, which are around $300 \mathrm{GPa}$ for $20 \mathrm{wt}$. \% additives and $360 \mathrm{GPa}$ for $7 \mathrm{wt}$. \%. The lower E value of the $\beta 7$ scaffold as 


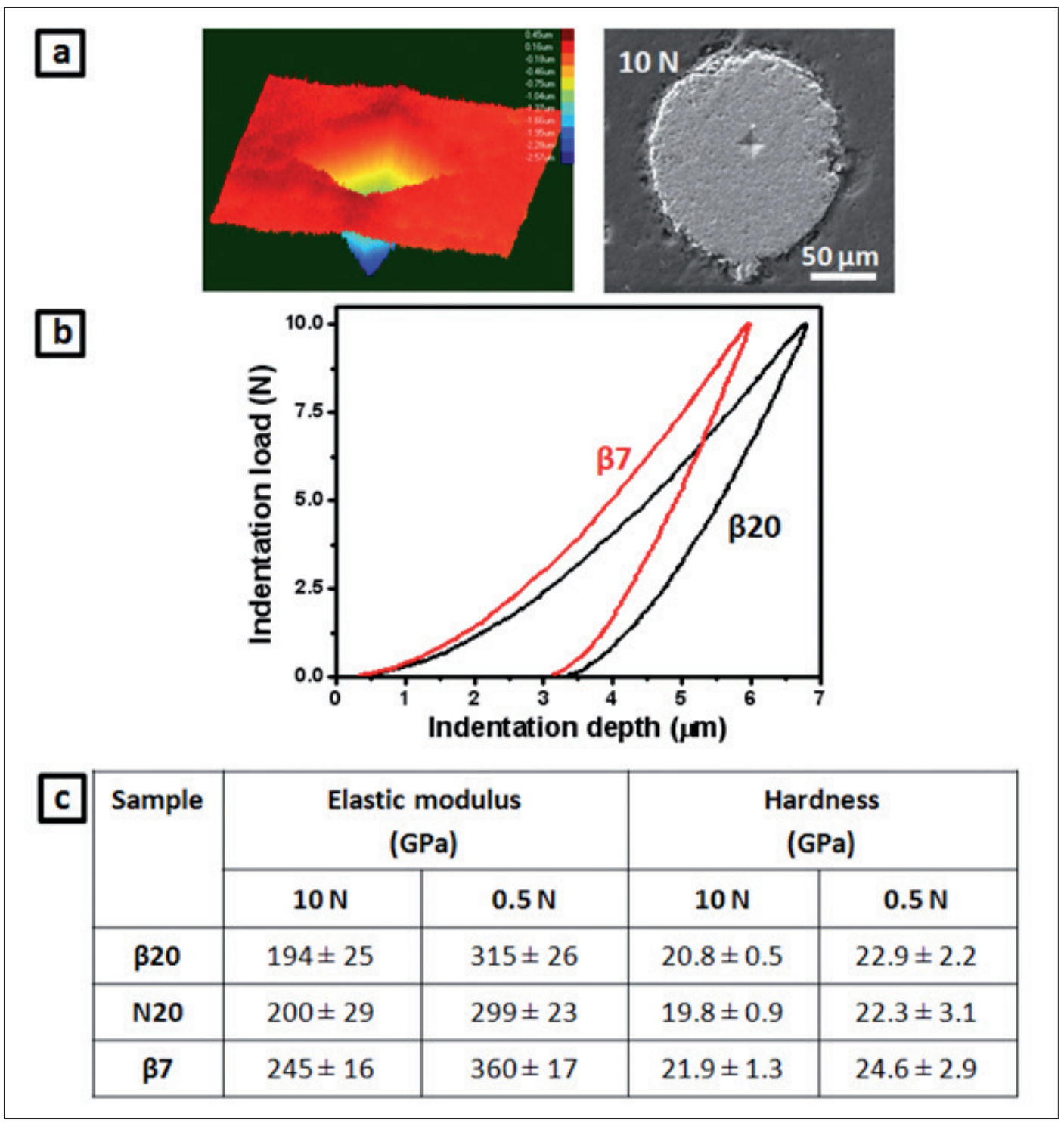

Figure 7.3D profilometry plot and FESEM image (a) of a $10 \mathrm{~N}$ indentation performed on the cross section of a rod belonging to N20 skeleton. (b)Indentation load vs. depth of two representative $10 \mathrm{~N}$ indentations on $\beta 7$ and $\beta 20$ structures. (c) Table summarizing the values for hardness and elastic modulus of the three different SiC ceramic materials.

compared to that of the bulk $\beta 7$ specimen (360 vs $406 \mathrm{GPa}$ ) may be partially due to its small remaining porosity. Data for the averaged hardness of the different $\mathrm{SiC}$ rods is also reported for both of the indentation loads used. $\mathrm{H}$ values were slightly lower for the N20 and $\beta 20$ than for the $\beta 7$ scaffolds, clearly associated to their higher amount of sintering additives. All of them are in the range of $\sim 20-22 \mathrm{GPa}$ for $10 \mathrm{~N}$ and, as it could be expected, they are slightly higher (22.3-24.6 GPa) for $0.5 \mathrm{~N}$ (Table in Fig. 7c). The $\mathrm{H}$ value measured at low loads $(0.5 \mathrm{~N})$ for $\beta 7$ scaffold is again lower than that of the bulk $\beta 7(29.6 \pm 0.7$ $\mathrm{GPa})$, because of its higher porosity.

\section{CONCLUSIONS}

Three different SiC-based colloidal inks with high solids loadings and pseudoplastic rheology have successfully been produced to accomplish the deposition by robocasting of complex 3D-structures, varying the amount of sintering additives and the particle size of the $\mathrm{SiC}$ starting powders from $0.5 \mu \mathrm{m}$ to $50 \mathrm{~nm}$. A direct relationship between the amount of organic additives and the specific surface area of the $\mathrm{SiC}: \mathrm{Y}_{2} \mathrm{O}_{3}: \mathrm{Al}_{2} \mathrm{O}_{3}$ mixtures has been established, thus extending the proposed formulation to further compositions of $\mathrm{SiC}$ inks. The shapes of the extruded filaments and the overall geometry of the deposited lattice structures are retained in all cases, even when using nanometric $\mathrm{SiC}$ powders that limit the solids loadings of the ink and increase the shrinkage during sintering. Small amounts of sintering aids (from 7 to $20 \mathrm{wt}$. \%) assured enough densification by SPS at relatively low temperatures $\left(1700-1800{ }^{\circ} \mathrm{C}\right)$ without any damage of the $\mathrm{SiC}$ structures. Temperatures reached in the SPS graphite die tool seem to be above those measured by the controlling pyrometer, producing a noticeable $\mathrm{SiC}$ grain growth and causing reactions between $\mathrm{SiC}$ and sintering additives, when compared with bulk specimens sintered alike. Indentation tests on the scaffold rods were strongly affected by the resin embedding used to allow handling, and true values of elastic modulus by indentation 
required loads under $1 \mathrm{~N}$. Hardness of the $\mathrm{SiC}$ rods is always in the range of $\sim 22-24 \mathrm{GPa}$, but the stiffness can be increased by $13-17 \%$ reducing the amount of additives from 20 to $7 \mathrm{wt}$. $\%$.

\section{ACKNOWLEDGEMENTS}

This work was supported by the Spanish Government under the project MAT2012-32944.

B. Román-Manso thanks the financial support of the FPI fellowship Program, and the scientific assessment of Dr. J.E. Smay and Dr. K. Cai during a stay in the Department of Chemical Engineering, Oklahoma State University, USA.

\section{REFERENCES}

1. L. J. Gibson, M. F. Ashby, Cellular Solids, Structure and Properties, 2nd ed. Cambridge University Press, Cambridge, UK, 1997.

2. M. Scheffler, P. Colombo, (Eds.). Cellular ceramics. John Wiley \& Sons, Germany, 2006

3. R. Brezny, D. J. Green, Mechanical behavior of cellular ceramics, Mat. Sci. Tech., 11, 463-516, 1991

4. D. S. Shwartz, D. S. Shih, A. G. Evans, H. N. G. Wadley, Porous and Cellular Materials for Structural Applications, Materials Research Society Proceedings Vol. 521, MRS, Warrendale, PA, USA, 1998.

5. D. J. Green, P. Colombo, Cellular Ceramics: Intriguing Structures, Novel Properties, and Innovative Applications. MRS Bull., 28, 296-300, 2003.

6. A. Woesz, M. Rumpler, J. Stampfl, F. Varga, N. Fratzl-Zelman, P. Roschger, K. Klaushofer, P. Fratzl, Towards bone replacement materials from calcium phosphates via rapid prototyping and ceramic gelcasting, Mater. Sci. Eng. C, 25[2], 181-186, 2005.

7. K. A. Schwetz, Silicon carbide based hard materials - Handbook of ceramic hard materials, Wiley Online Library, Weinhein, Germany, 2008.

8. G. Roewer, U. Herzog, K. Trommer, E. Müller, S. Frühauf. Silicon carbide-a survey of synthetic approaches, properties and applications. High performance non-oxide ceramics I. Structure and bonding. Springer 101, 59-135, 2002.

9. A. R. Studart, U. T. Gonzenbach, E. Tervoort, L. J. Gauckler, Processing routes to macroporous ceramics: a review. J. Am. Ceram. Soc., 89[6], 17711789, 2006.

10. J. A. Lewis, J. E. Smay, J. Stuecker, J. Cesarano, Direct Ink Writing of ThreeDimensional Ceramic Structures. J. Am. Ceram. Soc., 89[12], 3599-3609, 2006.
11. J. Saggio-Woyansky, C. E. Scott, W. P. Minnear, Processing of Porous Ceramics, Am. Ceram. Soc. Bull., 71 [11], 1674-82, 1992.

12. T. Ota, M. Takahashi, T. Hibi, M. Ozawa, S. Suzuki, Y. Hikichi, H. Suzuki, Biomimetic Process for Producing SiC “Wood”, J. Am. Ceram. Soc., 78 [12], 3409-11, 1995.

13. A.R. de Arellano-López, J. Martínez-Fernández, P. González, C. Domínguez, V. Fernández-Quero, M. Singh, Biomorphic SiC: A New Engineering Ceramic Material, Int. J. Appl. Ceram. Techno., 1 [1], 56-67, 2004

14. Y. W. Kim, S. H. Kim, I. H. Song, H. D. Kim, C. B. Park, Fabrication of Open-Cell, Microcellular Silicon Carbide Ceramics by Carbothermal Reduction, J. Am. Ceram. Soc., 88 [10], 2949-51, 2005.

15. H. Wang, I. Y. Sung, X. D. Li, D. Kim, Fabrication of Porous SiC Ceramics with Special Morphologies by Sacrificing Template Method, J. Porous Mater., 11 [4], 265-71, 2004.

16. U. T. Gonzenbach, A. R. Studart, E. Tervoort, L. J. Gauckler, Ultrastable particle-stabilized foams, Angewandte Chemie-Int. Ed., 45[21], 35263530, 2006.

17. J. E. Smay, G. M. Gratson, R. F. Shepherd, J. Cesarano III, J. A. Lewis, Directed colloidal assembly of 3D periodic structures, Adv. Mater. 14[18], 1279-83, 2002.

18. J. Cesarano III, R. Segalman, P. Calvert, Robocasting Provides Moldless Fabrication from Slurry Deposition, Ceram. Ind., 148, 94-102, 1998.

19. P. Miranda, E. Saiz, K. Gryn, A.P. Tomsia, Sintering and robocasting of $\beta$-tricalcium phosphate scaffolds for orthopaedic applications, Acta Biomater., 2[4], 457-66, 2006.

20. S. Michna, W. Wu, J. A. Lewis, Concentrated Hydroxyapatite Inks for Direct-Write Assembly of 3-D Periodic Scaffolds, Biomaterials, 26, 5632-9, 2005

21. K. Cai, B. Román-Manso, J. E. Smay, J. Zhou, M. I. Osendi, M. Belmonte, P. Miranzo, Geometrically Complex Silicon Carbide Structures Fabricated by Robocasting. J. Am. Ceram. Soc., 95, 2660-6, 2012.

22. K. Sun, T.-S. Wei, B. Y. Ahn, J. Y. Seo, S. J. Dillon, J. A. Lewis, 3D Printing of Interdigitated Li-Ion Microbattery Architectures. Adv. Mater., 25, 4539-43, 2013.

23. W. C. Oliver, G. M. Pharr, An improved technique for determining hardness and elastic modulus using load and displacement sensing indentation experiments. J. Mater. Res. 7[6], 1564-83, 1992.

24. P. Miranzo, C. Ramírez, B. Román-Manso, L. Garzón, H. L. Gutiérrez M. Terrones, C. Ocal, M. I. Osendi, M. Belmonte, In situ processing of electrically conducting graphene/ $\mathrm{SiC}$ nanocomposites, J. Eur. Ceram. Soc. 33[10], 1665-74, 2013.

25. B. Román-Manso, E. Sánchez-González, A. L. Ortiz, M. Belmonte, M. I. Osendi, P. Miranzo, Contact-mechanical properties at pre-creep temperatures of fine-grained graphene/ $\mathrm{SiC}$ composites prepared in situ by spark-plasma sintering, J. Eur. Ceram. Soc., 34[5], 1433-8, 2014.

Recibido:03/10/2013

Recibida versión corregida: 23/12/2013

Aceptado: 30/01/2014 